\title{
STANDARDIZATION OF PIPE FLANGES AND FLANGED FITTINGS.
}

By JOHN DEWRANCE, Member, OF LoNDoN.

The standardization of pipe flanges and of flanged fittings is a matter of great importance to both manufacturers and users, and it has during recent years received much attention in this and other countries. On 18th April 1902, Mr. Robert E. Atkinson (Member), of Leicester, read before this Institution a Paper in which he dealt in a most thorough and painstaking way with the position of the subject at that date. Largely as a result of Mr. Atkinson's Paper, and of the valuable discussion to which it gave rise, the matter was, in the following year, taken up by the Engineering Standards Committee, who appointed a Sectional Committee on Pipe Flanges to deal with the question. This Committee, at that date, included representatives of the Admiralty, the Institution of Mechanical Fingineers, the Institution of Electrical Engineers, the North East Coast Institution of Engineers and Shipbuilders, the Institution of Engineers and Shipbuilders in Scotland, the Institute of Marine Engineers, the Institution of Heating and Ventilating Engineers, the Association of Railway Locomotive Engineers, and the British Tube Trade Association, besides representatives of many important manufacturing firms engaged in the construction of pipes, valves, etc. This Committee held its first meeting on 30th June 1903, and from it there was formed a smaller sub-committee, entrusted with the task of studying details and carrying out any experiments which might be necessary. 
The sectional committee and sub-committee held in all thirty meetings, at which they received and discussed a great mass of information relating to existing practice, and also the data derived from various experiments carried out in the course of the inquiry. As a result, they embodied their conclusions in a Report* in which the flanges, etc., are standardized in four classes, viz.:(1) low-pressure standard, for steam pressures up to $55 \mathrm{lb}$. and water pressures up to $200 \mathrm{lb}$. per square inch ; (2) intermediate-pressure standard, for steam pressures over $55 \mathrm{lb}$. but not exceeding $125 \mathrm{lb}$. per square inch ; (3) high-pressure standard, for steam pressures over $125 \mathrm{lb}$. but not exceeding $225 \mathrm{lb}$. per square inch ; and (4) extra highpressure standard, for steam pressures exceeding $225 \mathrm{lb}$. but not exceeding $325 \mathrm{lb}$. per square inch. The report also gives standard dimensions for short bends and tees of cast metal and for long bends of wrought-iron and steel.

The work of the Committee necessarily demanded the careful consideration of a number of points of detail, it being especially desired to arrive at such standards as would, on the one hand, ensure efficient joints, and, on the other, avoid undue weight; while, moreover, it was necessary-in order to realize the full value of standardization-that the standards arrived at should be such as would be suitable for stocking in quantities by the makers of pipes, valves, etc. Some of these points may be considered separately.

Diameters of Flanges and Bolt-Hole Circles.-In the British Standard Tables of Pipe Flanges, the diameters of flanges and bolthole circles are uniform for all flanges intended for steam pressures ranging from $55 \mathrm{lb}$. to $325 \mathrm{lb}$. per square inch, slightly smaller flanges, however, being given for the low-pressure flanges forming Class 1, and intended for steam pressures up to $55 \mathrm{lb}$. per square inch. The diameters of bolt circles decided upon were the smallest permissible in the case of cast fittings, after making due allowance for the fillet at the root of the flange and without resorting to pin drilling to secure a flat bearing face for the nuts.

* British Standard Tables of Pipe Flanges, No. 10, Nov. 1904. 
Number of Bolts.-One of the most important points that came before the sub-committee for decision was, whether or not the number of bolts employed should in all cases be a multiple of four, and a great deal of discussion occurred before a conclusion was arrived at. Careful consideration was given to standards in which the number of bolts increased one at a time, and others where the number increased two at a time, and the opinions of a great number of engineers were asked and considered.

Fig. 1.-7-inch Cast-iron Pipe for Hydraulic Power. 1,200 lb. Pressure per square inch.
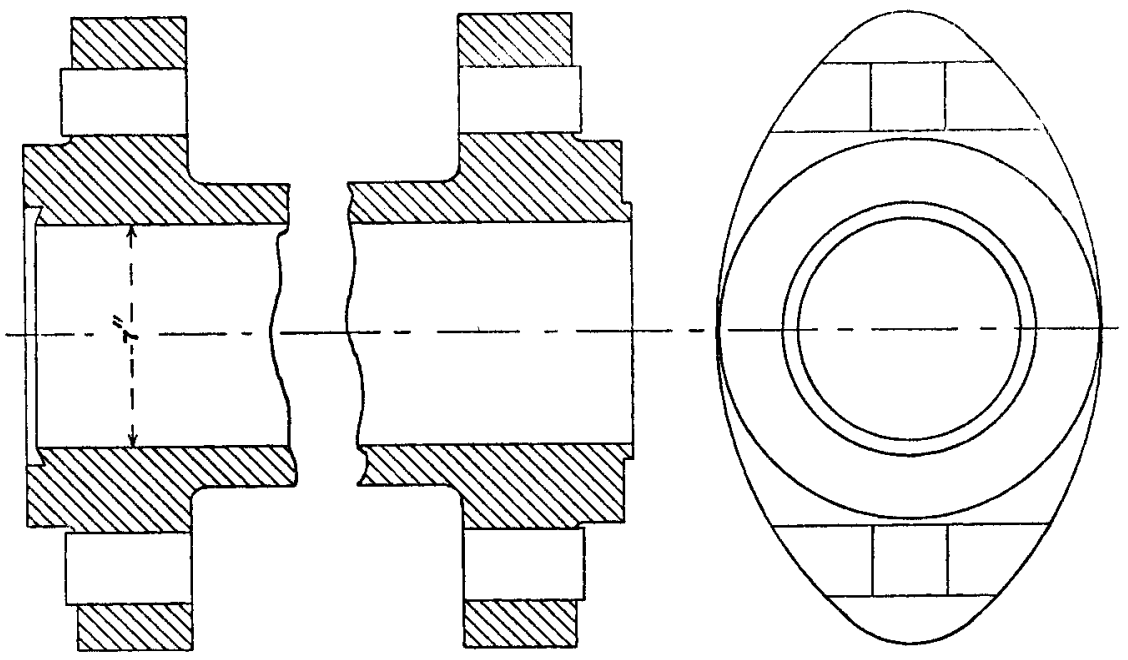

Every one present will be aware that hydraulic-press cylinders and heads are often connected by two bolts, and seldom by more than four. Cast-iron pipes up to 7-inch bore for hydraulic power up to $1,200 \mathrm{lb}$. pressure per square inch are made with two bolts.* Fig. 1 shows the 7 -inch size.

The reason only two bolts are used in the case of hydraulic mains is that several pipes are laid side by side in trenches in the

* See British Standard Specification for Cast-Iron Pipos for Hydraulic Power, No. 44. 
streets, but in order to be able to run the pipes in any direction, the standard tee bends and the valves must be made in three variations-one with the flanges vertical, another with the flanges horizontal, and still a third with one flange vertical and the other horizontal. This leads up to the conclusion arrived at by the sub-committee, that there can practically be no standard at all unless the numbers of bolts used are multiples of four.

It follows from the preceding paragraph that four bolts would be sufficient for even the largest steam-pipe flanges, but, in the larger sizes, the use of four bolts only would involve setting the bolt bracket back, as is done in the hydraulic pipe flanges. This would require longer bolts, which, of course, would have to be larger to stand the strain, and would entail a greater cost than the use of the number of smaller bolts that was adopted. In this respect, as in others, the sub-committee departed as little as possible from existing practice and followed the rule that, whenever room for four more bolts occurred, they were added.

The sizes of the bolts were calculated throughout to allow an ample margin of safety, assuming that, in the case of a joint on the point of leaking, the full pressure might be exerted on the area of a circle just touching the inside of the bolt holes.

The clearance of $\frac{1}{16}$ inch in the bolt holes for $\frac{1}{2}$ inch and $\frac{5}{8}$ inch bolts, and of $\frac{1}{8}$ inch for larger sizes, was, in the opinion of the sub-committee, the smallest allowance that was practicable for commercial manufacture.

Thickness of Flanges.-A considerable amount of the time occupied by the sub-committee was given to the consideration of the thickness of flanges. Many theories as to the formulæ put forward on this subject were considered, but the sub-committee did not agree as to any formula that could be accepted for general use.

The author's view is that two separate stresses have to be considered. The first is the stress necessary to distort the flange and the pipe considered as a cantilever, and the second is the stress necessary to cup the flange itself. To demonstrate this, a short piece of $2 \frac{1}{2}$-inch bronze pipe with two of the standard flanges, 
$7 \frac{1}{4}$ inches diameter and $\frac{1}{16}$ inch thick, was made and drilled with eight holes to the British standard. One flange was bolted up to a cast-iron flange and the other flange was connected by bolts to another thick cast-iron flange, leaving a space between the bronze and cast-iron flange, as shown by Fig. 2. The cast-iron flanges were then pulled apart in a testing machine. At $17 \cdot 28$ tons the lastmentioned bronze flange set $\frac{1}{3^{2}}$ inch and at $19 \cdot 2$ tons it set $\frac{1}{8}$ inch.

Fras. 2 and 3.-Tests on Bronze I'langes.

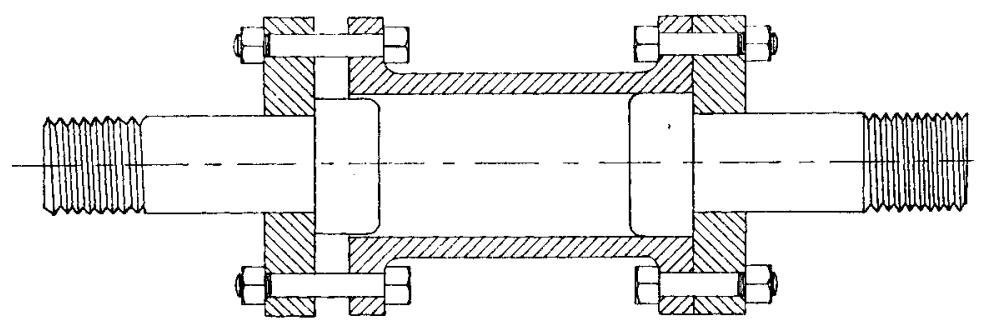

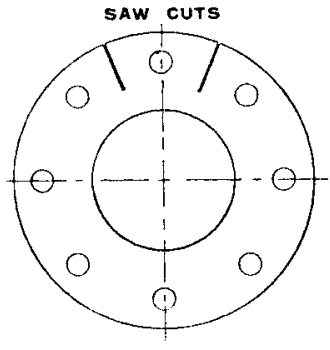

Front viow.

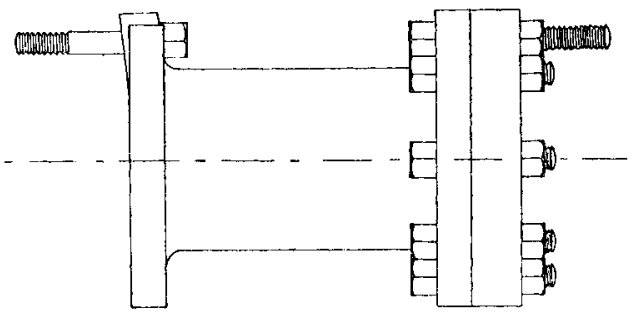

Side view.

Two radial saw cuts were then made in the undistorted flange, as shown in Fig. 3. These cuts bisected the distances between one of the bolt holes and the holes on either side of it, and ran down the radius from the outside circumference of the flange until they met the barrel of the pipe. In this way one-eighth part of the flange was isolated from the rest.

A bolt was passed through the hole in this isolated portion and another through the corresponding hole in the complete flange, and the cantilever strength of the small portion was tested between the 
centres of a testing-machine in the ordinary way, as shown in Fig. 3. A set of $\frac{1}{8}$ inch was obtained with a load of $1 \cdot 27$ tons.

This experiment proves that the flange owes $1 \cdot 27$ tons for each section of an eighth, or $10 \cdot 16$ tons in all, to the cantilever strength, and the balance of the 19.2 tons or 9.04 tons to the strength of the flange itself.

A flange $6 \frac{1}{2}$ inches diameter for 2-inch pipe, and having four bolts, was then taken and pulled in a similar way: at $14 \cdot 3$ tons there was a permanent set of $\frac{1}{32}$ inch, and at $16 \cdot 99$ tons a permanent

Fig. 4.-Flange with 4 Bolts.

13 tons permanent set $\frac{1}{64}$ inch. $15 \cdot 27, ", \quad, \frac{1}{8}$ inch.

Fic. 5.-Flange with 8 Bolts.

$5 \mathrm{lb} .10 \mathrm{oz}$. saved in weight.
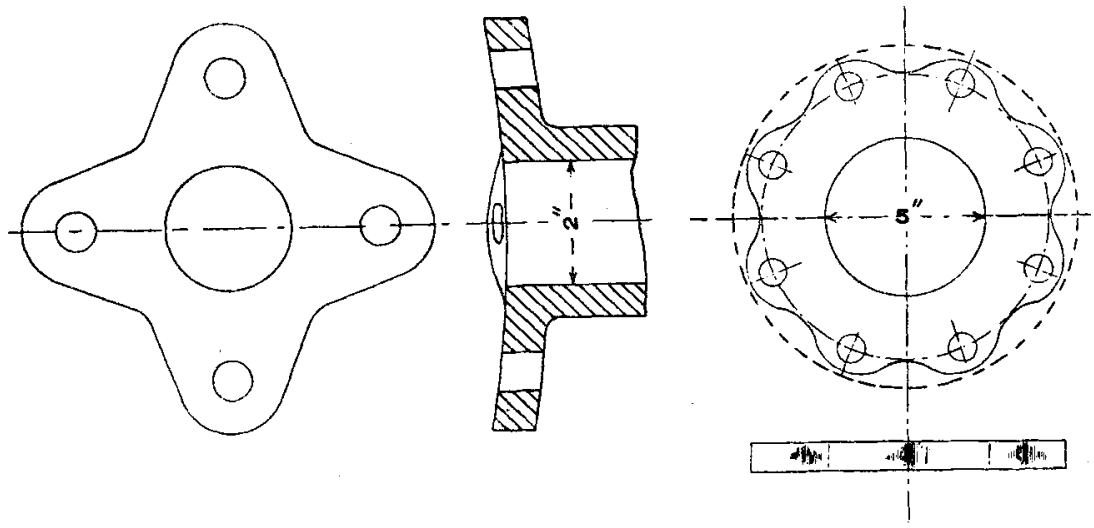

set of $\frac{1}{8}$ inch. An exactly similar flange was then reduced to the shape shown by Fig. 4. At 13 tons there was a permanent set of $\frac{1}{64}$ inch, and at $15 \cdot 27$ tons a permanent set of $\frac{1}{8}$ inch.

This result was extremely interesting, as the metal between the bolts on the line of the bolt circle having been cut away, it proved that formulæ based on strength of the girder between the bolts are not correct; it also proved that there is an ample margin of strength when four bolts are used for a 2 -inch flange.

The result of this experiment also suggests that, if it be very important to keep the weight down as low as possible, flanges need not be round, but might be of a shape similar to that shown by 
Fig. 4, or, in the case of eight bolts, by Fig. 5. Such flanges could be bolted to round flanges to the British standard and not be very unsightly. In the 5-inch size shown by Fig. 5, $5 \mathrm{lb}, 10 \mathrm{oz}$. would be saved in the weight of the flange.

The thicknesses of the flanges embodied in the standard Tables were arrived at by the sub-committee as the result of actual experiments conducted for them. These experimental flanges were jointed with red-lead paint and baked for 24 hours above steam heat; they were then tested till they leaked, and the thickness adopted in all cases showed a satisfactory margin of strength. The sub-committee, however, did not provide for test pressures more than $100 \mathrm{lb}$. in excess of the working pressures, and if greater test pressures of the complete pipe-lines were required, the thickness of the flanges would have to be increased. Hydraulic tests of individual units can, however, be made, with temporary elastic packings, to test the soundness of the material.

It will be understood that the stiffness of any given flange is largely dependent upon the distance between the exterior of the pipe or valve body and the bolt circle, and it follows that any reduction in the thickness of the metal of a pipe or valve casing weakens the flange. This effect is noticeable in the case of steel or wrought-iron pipes having welded-on flanges, a form of construction which is now so largely used. If the welded-on flange is provided with a boss or collar round the pipe, the conditions approximate to those of a casting; but if the flange is a plain disk, as is very generally the case, the increase in the distance between the bolt circle and the exterior of the pipe has to be specially taken into account in deciding the thickness of the flange.

It is for this reason that in the British Standard Tables of Pipe Flanges the thicknesses for steel or wrought-iron flanges welded on are made the same as for cast-iron flanges, notwithstanding the much greater strength of the flange material in the former case.

In dealing with this question, it is quite realized that if the necessity did not arise for coupling up pipes with welded flanges, to valves or cast metal tees, etc., smaller flanges could be used on such pipes with advantage. The Tables thus include one specially elating to welded-on flanges intended for use on long pipe-lines 
free from valves, etc. In this case the dimensions of the flanges are similar to those in the other standard Tables for steam pressures of from $55 \mathrm{lb}$. to $325 \mathrm{lb}$. per square inch, but for 2-inch pipes and upwards, the sizes of flanges used are those for the next smaller sizes of pipes in the other standard Tables. Thus the pipe-line size of flange for a 6-inch pipe is that for an ordinary 5-inch, and so on.

Jointing Material.-The sub-committee did not make any recommendations as to packings, though they discussed these. The author would, however, like to point out that the strength of a flange is much greater if the packing extends over the whole face. Packings that only extend over the surface inside the bolts throw an unnecessary stress on the flange and tend to cup it and cause it to break away from the pipe.

Some manufacturers hold that, by using their own standard sizes of flanges, they influence their customers to come to them for renewals and additions of plant; but as they must also be prepared to supply to British standard sizes, it is probable that any advantage they gain by retaining their own standard is counterbalanced by the extra cost of using two standards.

In cases of breakdown the enormous advantage to large user's of machinery, of a standard, cannot in general be over-estimated. Fittings of subsidiary machinery can in emergency be transferred to the most important uses. Spares are fewer and more generally useful, and renewals can often be obtained from stock; whereas special flanges require special fittings throughout, and this, in the case of cast-steel, involves a delay of weeks, that may be serious.

The British standard for pipe flanges is certainly the most largely adopted at the present time, and it is suggested to those members of the Institution who have not already adopted it, that they should give the matter their careful consideration.

The author wishes to thank the Engineering Standards Committee for the permission granted to him to quote from the Reports issued by that Committee; and he is much indebted to Dr. Maw for his assistance in the preparation of this Paper,

The Paper is illustrated by 5 Figs. 


\section{Discussion.}

The Chairman (Mr. Michael Longridge, Vice-President) said he was not surprised that the author and his Paper had been received with applause, because both appealed to instincts and propensities in which most men were fond of indulging. The author, like the Irishman at Donnybrook Fair, had taken off his best coat and trailed it behind him for people to stamp upon and try to tear to pieces. The Paper, in addition to describing the method by which the Engineering Standards Sub-Committee on Pipe Flanges had gone about its work, and giving the Members a difficult theoretical problem to solve at the top of page 88 , had also given, to those who had not been concerned in the preparation of the Sub-Committee's Report, an opportunity of explaining how much better they could have done the work if it had been committed to them. He believed the present was the first time that a Report of one of the Engineering Standard Committees had been deliberately put up as a target to be fired at, and if the Report in question stood the fusillade of the Members of the Institution, he thought it might be reasonably concluded that the recommendations the Committee had made were the best that could be suggested under the circumstances. If, on the other hand, valid and serious objections were taken to their recommendations, he was quite sure the Committee would take these objections into serious consideration at the next annual revision of their Report.

The Resolution of Thanks was then put and carried with acclamation.

Dr. William H. Maw (Past-President), in opening the discussion, said the author had given a plain and straightforward statement of the work of the Pipe Flanges Committee, and there was very little to add to the Paper so far as an account of their work was concerned. There were, however, several very interesting points in the Paper which were in the nature of by-products. Some of these related to 
(Dr. William H. Maw.)

the experiments made by Mr. Dewrance on the flanges of a $2 \frac{1}{2} \mathrm{~m}$. bronze pipe.

Referring to the tests illustrated by Figs. 2 and 3 (page 87), Dr. Maw remarked that the experiment on a segment of the flange which had been isolated by saw-cuts, as shown in Fig. 3 of the Paper, was marked by some very interesting features. In the case of a straight flange, if a certain length, bolted up by, say, three bolts, required a load of 9 tons to produce a given distortion, then if the flange was divided into three parts by saw-cuts midway between the bolts, it would still require a total load of 9 tons, or 3 tons per bolt, to produce the same distortion, as it would have been simply divided into three cantilevers with parallel sides. Such a flange might be regarded as representing the flange of a pipe of infinitely large size. But in the case of ordinary pipeflanges, the division into segments by radial saw-cuts produced cantilevers the width of which diminished inwards, as shown by Fig. 3 and on the left-hand side of Fig. 6 . In the case of the particular flange tested by Mr. Dewrance, the pitch of the boltholes was $2 \frac{3}{16}$ inches and the width of the isolated segment at its root was $1_{16}^{3}$ inch, or 54 per cent. of its width at the bolt circle. Now, the uncut flange required a load of 19.2 tons, or 2.4 tons per bolt, to produce a permanent set of $\frac{1}{8}$ inch, while in the case of the isolated segment the same set was produced by a load of 1.27 tons. But $1 \cdot 27$ ton was 53 per cent. of 2.4 tons, so that they had the curious result that the fact of the flange being uncut enabled it to offer a resistance practically equal to that which would be offered by eight segments, if it were possible for these segments to have parallel sides and a width equal to the pitch of the bolts. This showed the possibility of the uncut flange acting as if it were made up of a series of overlapping cantilevers, as indicated on the right-hand side of Fig. 6. If this were assumed, then the portions of the flange metal indicated by cross-hatching would be subject to compound stress, tending to produce distortion in different places.

If this assumption approximately represented the actual facts, it would follow that the portions of the flange outside the contour 
of the imaginary overlapping cantilevers might be cut away without affecting the strength of the flange. At the suggestion of the speaker, Mr. Dewrance kindly arranged to make an experiment on this point, and the tests of the flange shown in Fig. 4 (page 88) were the result. This "starfish" flange, as it might be called, gave a permanent set of $\frac{1}{8}$ inch with a load of 15.27 tons, while a circular flange, having a diameter equal to that of the "starfish"

FIa. 6.

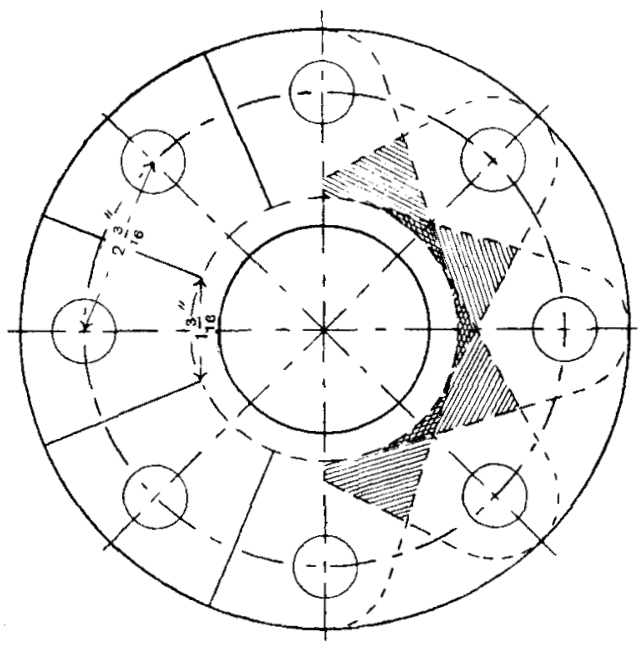

FIG. 7.

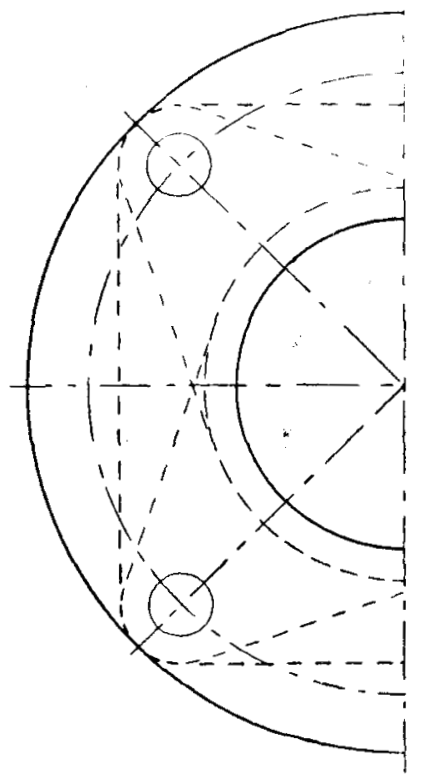

flange over the points of the rays, required 16.99 tons to produce the same set. In this case, therefore, there was a loss of strength of $10 \cdot 3$ per cent., due to the cutting away of portions of the flange, but the weight was reduced in a far larger ratio. The starfishshaped flange shown in Fig. 4 was, he thought, cut out a little too much, and a very slight filling up of the curves in the hollows of the flange would probably have given it the full strength of the round flange. 
(Dr. William H. Maw.)

The point to which he had called attention had a bearing on the success with which square flanges were used. One of the troubles experienced by the Committee, in drawing up the Standards, was that of getting people to believe that four bolts were sufficient for a 2-inch flange. This was rather curious, because there was an enormous number of flanges for 2-inch pipes in use in this country with only four bolts. Practically all the locomotive feed-pipes had flanges of that kind, and not only that, but English locomotive engineers for many years had been using regularly four bolts on 4 -inch and $4 \frac{1}{2}$-inch steam-pipe flanges. On looking into the matter, it seemed to him that this practice constituted a corroboration of the strength of the starfish pattern of flange. Fig. 7 (page 93) represented half a circular flange for a 4-inch pipe with only four bolts. It looked rather an undesirable thing to use, but if portions were cut off so as to give it the square form, also shown on the diagram, it looked much less objectionable. It would be noticed that the square flange sufficed to include the imaginary cantilevers to which reference had been made, and that the portions of the round flange cut away were superfluous. It seemed as if that result had been arrived at in practice by experience and not by any scientific reasoning. In the case of a flange with eight bolts, cutting away of the metal outside the imaginary cantilevers, to which he had referred, gave the form of flange which the author had illustrated in Fig. 5 (page 88).

He desired to refer to only one other small point, namely, the bronze pipe illustrated by Mr. Dewrance in Fig. 2 (page 87). It was worth notice that the pipe shown was quite a symmetrical one, the flanges at the two ends being alike, but one was bolted up tight to a thicker flange, and the other was separated from what he might call the testing flange by a space. In the experiments referred to, the loosely coupled flange to the left-hand side of the Figure was distorted, but the other was practically undistorted, although it had the same stresses on it. The author specially mentioned that the flange on the right-hand side was undistorted, and that he used it for another experiment later on. He wished to say, in conclusion, that he quite corroborated the Chairman's 
statement as to the desire of the Pipe Flanges Committee to have the fullest possible criticism of the work they had done. The Committee had held a great number of meetings, and had put a great deal of hard work into the matter. It was very gratifying to be able to state that last year the Committee received a letter from, he thought he might say, the largest pipe maker of the country, saying that his firm was now making 75 per cent. of its output of steam-pipe flanges to British Standard dimensions.

Mr. William H. Patchela (Member of Council) said he would prefer to have heard what the members present had to say on the Paper before he spoke on it himself, not only because he was on the Committee, but, as the Chairman had said, the present was perhaps the first time that one of the British Standards had been put up to be shot at. Had it been put up for that purpose when the Standard was new, something might have been said for it. He thought probably the reason for airing the matter at the present time was to bring one or two dissentients into line, because the Pipe Flange Standard had probably received nearer universal acceptation than any other of the British Standards. The author knew more about the Admiralty than he (Mr. Patchell) did, but he did not know whether the Censor would permit him to say what it was now doing in respect of pipe flanges. The last he heard was that they were not quite in accord with the British Standards.

Dr. Maw had referred to Fig. 2 (page 87), in which the tightly coupled flange stood, while the loosely. coupled tlange buckled. That, he thought, was due to the outer edge of the tightly coupled flange being kept in position, as it would have to go forward if the flange dished. The point that Dr. Maw referred to, with regard to the strength of the flanges, appealed to him more on the question of the joints. The worst part of a flange was the joint which had to be made in it. Some people were only concerned in making or selling flanges. At the time that the Pipe Flanges Committee was sitting he was engaged in buying flanges and using what he bought, which was sometimes an unfortunate position for putting one "in 
(Mr. William H. Patchell.)

the know." The experience he then obtained was that the thin flanges which were then the ordinary stock did not stand up to their work.

The author had referred to the advantage of putting the packings entirely over the face of the flange. That, again, was a point which appealed in one way to the man who was selling the flange and had to pay for the transport of it, and who would like to make the flange a little thinner, but it appealed in another way to the man who had to work the flange. An ordinary way of erecting pipes was to bolt them up in position, take out the top bolts, and drop the jointing material in, and if the joint had to be made all over the flange, it was a very different matter. So far as the use of jointing material was concerned, the ideal joint was metal to metal, scraped joints, but unfortunately they were too expensive. The author referred to some tests which were made for the Standards Committee on red lead which was baked. That approximated to the ordinary commercial joint. The Taylor ring was used perhaps more than that method, but it was often abused by the corrugations of the ring being blocked up with something which would not yield. It was sometimes advisable to use a material which did not bake hard, but retained a little flexibility. Many years ago it was possible to get a flexible sort of cheap rubber for the purpose. With such joints, after the main had been let down cold, it would leak a little when the steam was turned on, but it very soon warmed and would take up. At a subsequent date he bought what was sold as the same material, but he found that after letting the main cool, leakage took place when steam was put on again. $\mathrm{He}$ then ascertained that the material had been altered in its manufacture, and by being baked had lost its resiliency.

The author might, he thought, have given further details in connexion with the tests of the flange mentioned on page 87 , as an interesting record existed with regard to that matter. As Dr. Maw had stated, it was doubted whether four bolts would hold up for a 2-inch pipe. He believed the Americans went up to $2 \frac{1}{2}$ inches for four bolts, whereas the English practice was to draw the line at 
2 inches for four bolts. At the time to which he referred, the author made some tests, a short reference to which might be useful and permissible. The tests were of $2 \frac{1}{2}$-inch bronze flanges, $7 \frac{1}{2}$ inches diameter, $\frac{3}{4}$ inch thick, with four $\frac{3}{4}$-inch bolts, on a $5 \frac{7}{3}$-inch bolt circle. First with joints turned only. With a Cooperite joint $\frac{1}{1+7}$ inch thick inside the bolts, leakage occurred at $1,500 \mathrm{lb}$. pressure; with red lead heated before testing to $380^{\circ} \mathrm{F}$. for 12 hours, leaknge occurred at $200 \mathrm{lb}$. pressure; with $\mathrm{a}$ corrugated ring thickly coated with plumbago stuck on by spirit, varnish, leakage occurred at 1,700 lb. pressure; with a corrugated ring thickly coated with plumbago stuck on by spirit varnish, but heated to $380^{\circ} \mathrm{F}$. for 12 hours, the leakage occurred at $1,200 \mathrm{lb}$. pressure; and with plumbago stuck on with spirit varnish inside the bolt circle, leakage occurred at $50 \mathrm{lb}$. pressure.

Then the author carried out some experiments on similar flanges turned and scraped to a perfect surface inside the bolt circle and eased off beyond. With four $\frac{3}{4}$-inch bolts, and Cooperite $\frac{1}{16}$-inch thick full diameter of flange, leakage occurred at 1,500 lb.; with thin red lead on the scraped surface it occurred at $350 \mathrm{lb}$; and with thin red lead as previously stated, but heated to $380^{\circ} \mathrm{F}$. for 24 hours, it occurred at $350 \mathrm{lb}$. Then with six $\frac{5}{8}$-inch bolts, with thin red lead not heated, leakage occurred at $1,300 \mathrm{lb}$; ; with thin red lead heated to $380^{\circ} \mathrm{F}$. for 24 hours, at $1,350 \mathrm{lb}$. Further tests with eight $\frac{5}{8}$-inch bolts with thin red lead not heated, leakage occurred at $1,700 \mathrm{lb}$; and with thin red lead heated to $380^{\circ} \mathrm{F}$. for 24 hours, at $1,750 \mathrm{lb}$, so that the result with six bolts instead of four on a $2 \frac{1}{2}$-inch flange gave a minimum of $1,300 \mathrm{lb}$. Those figures were, he thought, rather useful as showing how joints might be made. About the same time the Admiralty made some tests on 12-inch and 15-inch flanges. The flanges that were available were not thick enough to stand up to the work; they all leaked in the preliminary tests at $500 \mathrm{lb}$, and the best of them stood $600 \mathrm{lb}$. Instead of waiting for further flanges, those particular flanges were cambered so that when two were put together there was a gap of $\frac{1}{32}$ inch at the outside edge. A 12-inch flange under those circumstances stood 1,100 lb. pressure, and the 15 -inch which had 
(Mr. William H. Patchell.)

failed at $400 \mathrm{lb}$. when flat, failed at $900 \mathrm{lb}$. That showed how the best could be made of a bad job; but he would not recommend anyone to buy cambered flanges.

He hoped the Institution would hear what objections there were, if any still existed, to the adoption of the British Standard flanges, because everything was to be said in favour of a uniform standard. Nothing was more annoying, if an engineer was buying a piece of machinery, than for him to have to telegraph at the eleventh hour, especially nowadays, when the question of prompt delivery was of the utmost importance, asking if the flanges were British Standard size.

Mr. E. J. Fox thought the Chairman was quite safe in inviting engineers to criticize the efforts of the Standards Committee on the subject of flanges, as the standards had been largely adopted both by manufacturers and users and had proved a success. Speaking as the representative of the largest firm in this country manufacturing this class of material, he could say that, with one exception to which he would refer later, the dimensions of the Standards Committee had been adopted and were their (Stewarts and Lloyds') Standards. The Admiralty and Marine Engineering firms had, however, not adopted these standards. With those two exceptions, users were largely adopting the dimensions of the Standards Committee, from which he presumed that every manufacturer was also working to them. The particulars contained in the Report laid down dimensions which were economical from a manufacturing point of view. The size of joint was as cheap as it was possible to make it for the duties specified.

Those of the members who were not thoroughly familiar with the details of the Report would be interested to know that one Table, namely, Table 2, contained the dimensions of steel flanges for use in connexion with steel pipes, and the thickness of those flanges was the thickness of cast-iron flanges. At first sight it might appear that steel flanges might be made a good deal thinner than cast-iron, and to some extent he personally thought that that was the case; and certainly many engineers were willing to accept 
lighter flanges. But the point to which the author had referred was that a flange, however strong in itself, when attached to a comparatively thin body was liable to "give," and consequently was not as rigid as a cast-iron flange on a cast-iron pipe. For that reason the dimensions given in Table 2 were those in use for castiron flanges. But as an alternative a further Table, namely, Table 3, was introduced, in which smaller dimensions were adopted for steel flanges for use in those cases where the flanges were welded on the steel pipe.

He desired to take the present opportunity of slightly departing from the direct subject of the Paper to emphasize the great superiority of steel flanges welded on steel pipes over steel flanges either screwed on or riveted on. From the point of view of obtaining a satisfactory joint, if the dimensions of the flange were kept down in diameter and in thickness, as set out in Table 3, it followed that a stiffer joint was obtained; further, he thought most engineers were now agreed that the welded-on flange made a more satisfactory joint when compared with a flange riveted on or screwed on. It was advisable, however, to avoid a plain parallel flange: and it was equally important to avoid a flange with a large boss on it. The medium between the two, that is, a large fillet on the back of the flange, was really the ideal, and represented the best practice at the present time for flanges to be welded on pipes.

He now came to the important exception, to which he had already referred, where it had been found difficult-indeed, he might say, from a commercial point of view, impossible-to work to the standard dimensions, namely, in connexion with steel pipes with loose flange-joints. Loose flange-joints, as members knew, represented an important portion of the steel-pipe trade. It was not unusual to get lines of steel pipes with loose flanges up to 40 and 50 miles in length. The Standards Committee had adopted, quite rightly as far as practice generally was concerned, multiples of four for the number of bolts in flanges. The old practice, however, in connexion with loose flange-joints had been multiples of two, and in so far as loose flange-joints were generally used in long lines where valves, fittings and special material of that description 
(Mr. E. J. Fox.)

was not much used, it mattered comparatively little whether the dimensions set out in Table 2 were departed from, and consequently the old standards were retained. He did not know whether he had made the point quite clear. The loose flange-joint was the cheapest form of joint possible in connexion with steel pipes. It was the cheapest form, because it enabled the use of a thinner pipe than where a flange was rigidly attached either by welding or riveting to the pipe itself. And as cheapness was the primary consideration, the new standards were not adopted in connexion with this class of pipe.

He asked permission to refer to one point in passing, because, although it was not directly concerned with the subject matter of the Paper, it was of interest. Flanges, after all, were merely a means of joining together two pipes. The application that had been introduced during the last two or three years of welding together by oxy-acetylene two lengths of pipe on sight and displacing other forms of joint, including the lead joint, was an application that was likely to be extended very considerably in the future. It gave practically the only form of joint which was as strong as the pipe itself, and which on a tensile test would more often than not break off the joint, which was as cheap as the ordinary lead joint where gas was available, and which was permanent. It was easy to make other forms of joint which were tight when made, but which were liable to start leaking in the difficult conditions of traffic under which joints had nowadays to work. In conclusion, he felt, speaking on behalf of a manufacturing firm, that they owed a debt of gratitude to the Standards Committee, with which the author and Dr. Maw had been actively associated in standardizing pipe flanges, for having given manufacturers standards to which to work.

Mr. H. F. RuTren said that as a user of flanged work he desired, in the first place, to bear testimony to the immense advantage and convenience which had accrued since the use of standard flanges had become general, and he felt sure engineers could look forward to the time when that use would become universal. His object in 
rising was to make a suggestion to the author, for his consideration and conveyance to the other Members of the Committee: it was that they should extend the list of flanges in regard to which they had already laid down standard dimensions. The largest flange with which the Committee had dealt up to the present time was a flange suitable for a pipe of 24-inch bore, but that did not go far enough. For steam purposes, especially in the present day of superheat and consequent small steam-pipes, it might be far enough, but engineers, who had to deal with water, had to use pipes of very much larger dimensions. They experienced very frequent inconvenience from the fact that there was at present no uniformity among the makers of stop-valves, reflux valves, and other fittings of that sort, with the result that they were put to the inconvenience of drilling boltholes on the ground, whereas they might just as well have been drilled under a machine. He therefore suggested to the author that the sizes of pipes dealt with should be extended to include the following:- $-30,33,36,42,48,54$, and 60 inches.

Mr. J. Anthutr Atron said it spoke well for the work of the Standards Committee that there was very little to criticize after ten years' usage of the Standards that they had prepared. The nembers had been told that the largest maker of steam-pipes made 75 per cent. of them to Standard dimensions, and they had heard that another of the largest makers, who said he was the largest maker, made all his pipes to Standard. Personally, he made a few steam-pipes, and when an application was made to him for anything outside the Standard, he charged extra because it cost more to make.

With regard to the various Tables that had been given in the Standard specifications, he desired, if he might be so presumptuous, to suggest that in Table 2, columns 7, 8 and 9 should be entirely cut out, for the following reasons. He did not think that a body, of the standing of the Engineering Standards Committee, should countenance such an antiquated and out-of-date thing as cast-iron for steam-pipes. Furthermore, they had heard what the author had said about welded pipes, which was the other direction in 
(Mr. J. Arthur Aiton.)

which those particular columns were used. So far as his own experience went, he wished that the Standards Committee had stated plainly that the column to which he referred was for flat welded-on flanges and not flanges welded with a collar. Despite what one of the previous speakers had stated, he knew that flanges with a collar were very successfully welded on to pipes. It was purely a question of the method of welding. If the welding were done by what was called the fire process-that is, heating the flange and the pipe in a fire and hammering - he did not think any more successful method could be adopted than to have a good stiff collar on the flange; but if the welding were being done by the electrical or any other process, then he quite agreed that the collar was not an advantage at all.

He thought the oxy-acetylene method was never used for such heavy work as the welding-on of flanges, but if the electric method were used, a very large and ample fillet ought to be provided, for two purposes. In the first place, it allowed for an extra amount of metal. He did not think that even the strongest supporter of electric welding would say that the metal which was deposited was equal to the metal of the pipe or the flange, and it therefore allowed a large amount of metal to bring up the strength of the joint by an amply heavy fillet-he did not mean a small thing about $\frac{3}{8}$-inch radius, but a heavy fillet. That stiffened the back of the flange, and it brought the flange almost up to the state of a flange with a big collar on it; furthermore, the position was raised up where it was being attached to the pipe. The attachment of a heavy flange to a light pipe was strengthened, a point which had been raised by one of the previous speakers. For those reasons he suggested that the three columns to which he had referred were unnecessary, and led to confusion.

He had personally experienced a considerable amount of confusion through engineers specifying the Standards Committee's dimensions, and when they were given the figures in column 11 , they replied that they expected to get the figures in column 8 , and it was then necessary for the manufacturer to point out that that column referred to a flange without a collar on the back of it. He 
further suggested that the Committee should leave out all the starred sizes except $4 \frac{1}{2}$ inches, because the other sizes, 9, 11, 13 and 17 inches, were bastard sizes that could very well be dispensed with. Table 1 was very good so far as it went, but engineers had advanced in the last ten years, and it did not now meet all the purposes required. Mr. Rutter mentioned that it did not meet the purpose of large water-pipes, and it certainly did not meet the purpose of large low-pressure steam-pipes such as were used with turbines. Those pipes were made up either by riveting or by welding, and the flanges usually consisted of a rolled-up ring of angle-bar either riveted or welded to the pipe. He would not suggest that the test pressure required for those pipes should be more than $30 \mathrm{lb}$., and therefore those flanges could and would have to be kept thin because of the method of manufacture. It was difficult to obtain those flanges more than $\frac{3}{4}$ inch thick. He suggested that it was not necessary in those flanges to increase the size of the bolts, as was done regularly as the sizes went up, and he contended that a 1-inch bolt was ample for all purposes, even up to 72-inch flanges. It was only a question of putting in enough of the bolts. He suggested that the circumferential pitch-circle should in no case exceed 7 inches; $6 \frac{1}{2}$ inches was about enough. With thirty-two bolts on a 60 -inch pipe, a pitch of about $6 \frac{1}{2}$ inches would be obtained, which he did not think would be excessive either for the number of bolts or for the pitch, and he thought a very satisfactory joint would be made in that way $\frac{3}{4}$ inch thick.

With regard to the vexed question of jointing material, he was perhaps treading on rather dangerous ground, especially after what had been said by Mr. Patchell, who suggested that it was the contractor's business to put up the pipes and get rid of them. His experience as a contractor was that neither Mr. Patchell nor any other engineer would let a contractor off who erected such work quite as easily as that. There was such a thing as reputation to be considered; and it was not worth any contractor's while to put up a set of pipes which leaked at the joints continuously after he had done with them. It had been his practice for many years only to use joints inside the flange, and that was done of "malice 
(Mr. J. Arthur Aiton.)

aforethought." He did not consider that putting a joint all over the flange strengthened the flange in the very least-that is, if a flange was going to cup, it would cup whether there was a joint all over it or not. The only difference, to his mind, was that if it cupped with the joint inside the bolt-holes, it would tighten the joint, whereas if it cupped with the joint outside the bolt-holesthat is, if it cupped through the stress of its work-leakage would be obtained between the pipe and the bolt-holes, which was just as bad as if it were obtained through the flange entirely. His experience of the use of Taylor rings was that they were very satisfactory-in fact, 95 per cent. of the joints which he supplied were Taylor rings; but, like everything else, they must be used with discretion. One of the great faults with those rings was to put a heavy mastic joint on them; in his opinion, they should be painted. The jointing material, which should be put on with a brush, should be quite thin. If a joint of heavy putty were put on, it defeated the aims of the rings entirely, because they could not then be compressed. The stiff putty was locked up within the corrugations, the joint thereby being made inefficient, whereas if the joint was simply painted it had a chance of "squashing" up and doing what was required.

One of the previous speakers had referred to the oxy-acetylene welding of pipes in position. He had had no personal experience of that operation, and had always avoided it, because he was afraid to use it. His own experience of oxy-acetylene welding was that to make a satisfactory weld, the welding position must be on the top or near the top of the pipe, and he had never yet been able to understand how anybody could weld successfully, by the oxyacetylene process, a range of pipes which had bends in it which could not be turned round. He had heard of that being done, but he did not believe it could be accomplished successfully, and he would be very sorry to trust his life to such a weld.

So far as the Paper was concerned, he would perhaps be excused for saying that he was disappointed with it. As a historical Paper of what was done ten years ago it was most interesting, but he did not think the historical point of view was the object with which the 
Paper was written. He thought that a great opportunity had been missed, because there were so many vexed questions in connexion with steam-pipes that might have been raised. For instance, there was the old argument as to whether lap-welded or solid-drawn pipes should be used, and also the question of the thickness of the pipes. A little had been said that evening about the method of fixing the flanges and the question of the jointing material, while the question of the method of fixing branches might also have been discussed. So far as the fixing of branches was concerned, ten years ago oxy-acetylene and other forms of welding were very much in their infancy, but nowadays the use of cast-metal branches was practically out of date. There were only two methods at present used, namely, riveting on or welding on.

Then the question might have been raised of whether the welding should be done by the oxy-acetylene process, by electricity, by the ordinary carbon arc, or by the newer system known as the quasi-are system. Personally he had never been able to find an oxy-acetylene joint that was up to the full strength of the plate. He had made and tested a few such joints, but he would never dare to claim that that was so. He had not even found a carbon-arc joint which was up to the strength of the plate, but with the later quasi-arc, which used a semi-arc and a special form of electrode, by the thickening of the joint which took place, he had found that the breakage occurred not at the joint but 3 inches or 4 inches back from it. By that method he had found something which was certainly up to the strength of the plate, or could be made up to the strength of the plate. He did not claim that, if it were kept to the same thickness as the plate, it would be up to the same strength, but by the deposition of metal the joint became thicker, and was therefore up to the full strength of the plate. As he had already mentioned, he suggested that the Engineering Standards Committee should devote some attention, in its revision of the Specification, to the provision of Standards up to 72 inches for use with turbines, as commonly used with riveted pipes or pipes made by various welding processes. $\mathrm{He}$ would like the Committee to make some statement as to what they 
(Mr. J. Arthur Aiton.)

considered to be the right thicknesses of pipes, because at present they varied enormously. He also thought that if this Institution could devote its attention to the question of the fixing of flanges and branches, and the other vexed questions which he had mentioned, they would be serving a very useful purpose.

The Chairman said he regretted to hear Mr. Aiton say that he preferred a joint made with a ring entirely inside the bolt-holes. No doubt a tight joint could be made that way, but he was perfectly satisfied, from long experience, that with cast-iron flanges at least, joints made in this way were dangerous. With wrought-iron or steel pipes there was less risk, but he was sure that the stresses produced by screwing up the bolts, where the support was entirely inside the bolt circle, often produced dangerous strains. He thought that Fig. 2 (page 87) proved the advantage of making the joint over the whole face of the flange, because it showed that the flange which was supported all over held good, while the flange which was not supported was deformed by the tension of the bolts.

With regard to the question of fixing flanges, he preferred welded flanges with collars, but as he had seen cases where such welds were only sound at the edges of the collars and thought it highly probable that there were many similar cases, he advocated riveting in addition to welding, so that if the welding gave way, the collars could not be drawn off the pipes.

He desired to say a word about the interesting romarks that Dr. Maw had made in regard to the relation between flanges and cantilevers. Personally, he could not see any connexion whatever between the two. If a flange became cupped, either the diameter of the outside edge of the flange must be diminished or the width of the flange radially must be increased. In the one case the material was compressed, and in the other it was stretched. In either case the resistance of the flange to deformation increased as the quantity of material to be compressed or stretched increased. In the cantilever the addition of material outside the bolt-hole would not increase the resistance to bending by a stress applied at the bolt-hole. In the undivided flange the addition of material 
outside the bolt-circle would increase the resistance to cupping. The determination of the amount of this increase of strength was the difficult theoretical problem he had referred to in his opening remarks. The Sub-Committee had apparently failed to find a satisfactory mathematical solution, and had relied on experiments to determine the thickness of the Standard flanges. It would have added much to the value of the Paper if these experiments had been described. It might happen that the effective strength of the particular flange, referred to by Dr. Maw, was the same as that of a number of cantilevers whose base was equal to the pitch of the holes, but it did not at all follow that the same relation held for pipes and flanges of other diameters. He thought the points the Committee ought to have determined, and perhaps they did determine them, were, first: the best relation between diameter of flange and its thickness, and, secondly, the thinnest flange that was required to make an effective joint.

Mr. William H. Patchell said that Mr. Fox had mentioned the question of welded joints. He remembered some time ago being on an undertaking where a condenser could not be placed close to a turbine and a 6 or 7 -foot diameter wrought-iron exhaust pipe of some considerable length was to be welded up. The contractors got on very well with the work until a frost came on, when they found it absolutely impossible to weld the last joint, as they could not get up the temperature, and they were obliged to put on a muff joint. That opened his eyes to the possibilities and limitations of joints welded in situ.

Mr. E. J. Fox said he desired to be allowed to make a few further remarks on the subject of oxy-acetylene welded joints in connexion with steel pipes. Although the system was a comparatively new one, it had been adopted by between seventy and eighty gas and water undertakings in this country during the last two years, so that any practical difficulties had been overcome. One of the previous speakers had mentioned the subject of welding underneath. That was a difficulty which it took much experimenting 
(Mr. E. J. Fox.)

to overcome. The difficulty of welding underneath, without dropping down the soft Swedish iron which was used as a welding material, was overcome in a simple way by the shape of the socket where the spigot entered it. There was just sufficient curvature to hold the molten material whilst the welding was going on.

It might be stated that the spigot was a driving fit in the socket, and the process of welding consisted in filling in the gap in the socket with soft Swedish iron-in other words, in rigidly welding together the spigot and socket. Mr. Patchell had referred to the difficulty of making that form of joint when other pipes were in the locality. It stood to reason that this form of joint could not be made unless it was accessible, but there were few cases where this was impracticable. A lead joint could sometimes be made at a distance of a couple of feet, but that was not often necessary. As a rule, it was possible to get at the joint sufficiently closely to make it. The welded joint to which he liad referred could be guaranteed as strong as the pipe itself, and, as already mentioned, was more likely than not, on a tensile test, to break off the joint.

The Chairman, in dealing with the question of welding the undersides of pieces, said he had seen a very interesting process a short time ago at Liverpool for welding up cracks in boilers in steamships. One of the terminals of the arc was the welder and the other was the boiler itself. One feature of the process was that the bits of iron which were put in were held up to the boiler by magnetism, while the welding was being carried out. It was a German process; he did not know whether it was in existence now, or whether it had gone back to Germany. Cracks, flues of the furnaces, and flanges of end plates were being welded with the greatest ease.

Mr. John Dewrance said there were very few points to which he had to reply. Most of those who had spoken had asked if he would impress upon the Standards Committee that further work was required, and when a Committee was asked to do more work it was fair to presume that the work they had already done had been 
satisfactory. Mr. Aiton suggested that he (the author) had missed a great opportunity of going more fully into the question of the construction of the different materials and the method of manufacture of pipes, but that was not the object of the Paper. As he understood it, the object of the Paper was to put upon the Proceedings of the Institution some record, belated as it might be, to the effect that the subject had not been allowed to rest as it was left by Mr. Atkinson in the Paper to which reference had been made. It was therefore confined simply to the subject of the standardization of flanges and not to the material and construction of the pipes. The changes in material and in the uses that had taken place since the standards were fixed had been considerable, but he did not think Mr. Aiton was quite right in suggesting that the use of cast-iron for bends, tees, valves, and fittings had been entirely done away with at the present time. There were still a great many fittings that were made of cast-iron, especially for the lower pressures, and he did not think the Committee could be expected hurriedly to omit all reference to that material.

Dr. Maw had given a very interesting criticism on the subject brought forward in the Paper as to the strength of the flange, but Mr. Longridge had practically supplied what he (the author) intended to say in answer to Dr. Maw. He did not think Dr. Maw intended the members to go away with the impression that the flange was entirely without strength, because that would be almost the inference of the figures Dr. Maw had given. There was no doubt it took a certain amount of power to cup the flange, and something must be allowed for it.

Mr. Longridge asked how the Committee determined the thicknesses of the flanges. All the determinations were empirical. He did not think there was any case in which they failed to get some member of the Committee or some body to make tests for them in the way explained in the Paper. Right up to the 24-inch size, if his memory served him correctly, actual experiments were made. It was rather amusing to him to remember that, to begin with, the Committee was bitterly condemned by the pipe-makers for the lavish waste of material they suggested shonld be put into 
(Mr. John Dewrance.)

the flanges. Their critics were ultimately induced to attempt to prove to the Committee how stupid they were, and they carried out some very costly and interesting experiments to show how excessive the thicknesses were. But the result of the experiments had the effect of converting the makers entirely; indeed, in one or two instances they suggested that the Committee should still further thicken the flanges, because it was quite clear that those which had been in use up to that time could not possibly be kept tight without some elastic packing, which, as all the members knew, was unsuited to superheated steam.

The suggestion which had been made, that Standards should be drawn up for larger pipes up to 60 inches, he would report to the Committee at the first opportunity, but he thought it was 9 little beyond the scope of the work they undertook at the time. Such large pipes would be used more for water purposes, whereas the Committee had steam-pipes and general pipes under their consideration. He thanked the members very much for their reception of the Paper, and for the discussion that had been raised on it, and he hoped there were not any very severe critics who had been kept away from the Meeting by the bad weather.

\section{Communications.}

Mr. C. HUMphreY W ING FIELD wrote that, like all Mr. Dewrance's communications, this Paper was very interesting. He gathered that the author had no intention of raising a discussion as to the propriety of the conclusions reached by the Engineering Standards Committee, but rather of drawing attention to them, and showing the adequacy of the proportions recommended in their Report.

The author's experiments showed that when metal was removed from between the boits in order to reduce weight, this might be done to a greater extent where the bolts were widely pitched than where they were close together. In each case the "bracket" of metal carrying the bolt should increase in width as it approached the pipe (see Figs. 4 and 5, page 88).

He had plotted the author's experiments in Fig. 8, adding 
lines (the precise form of which, of course, had no special significance) to connect the dots and show their relative heights. This diagram showed how much less the strength was affected by cutting away the metal of the flange with four bolts, in which the width of the bracket increased as it approached the pipe, than in the case of the flange with eight bolts, Fig. 3 (page 87), in which the reverse was

FIG. 8.

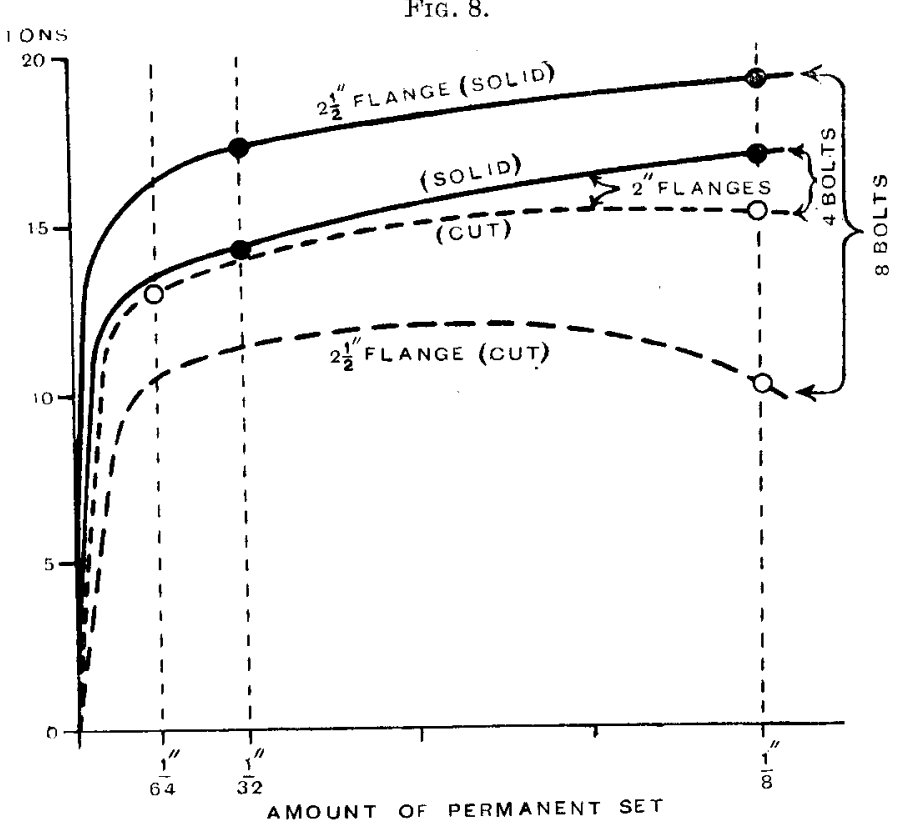

the case. In the latter the loss of strength was $\left(100 \times \frac{10 \cdot 16}{19 \cdot 2}\right)$, or about 53 per cent., whereas in the former it was only $\left(100 \times \frac{15 \cdot 27}{16 \cdot 99}\right)$, or about 9 per cent. The indentations shown in Fig. 5 (page 88) were of practically identical proportions with some with which he was familiar some 30 years ago, and he might say that no trouble had been met with on the score of strength. They were, however, open to the objection that, when two flanges of the same size were bolted together, their angular position did not always 
(Mr. C. Humphrey Wingfield.)

agree exactly,* and a certain amount of chipping became necessary for the sake of appearance, and it was found advisable to avoid this by casting one flange slightly larger than the other. In some instances one flange was circular, as suggested by the author.

The writer had not met with the suggestion (page 88) that the thickness of a flange should be determined by the strength of the metal between the bolts, regarded as a beam. The late Mr. Thomas Box had pointed out that, in the riveted seam of a boiler, the space between rivets might be regarded as a beam, the flexure of which would allow of leakage, and was of opinion that for equal freedom from leakage (pressure and other things being the same) the thickness of plate should vary as the fourth power of the width between the sides of adjacent rivet-holes. He did not know if this was what the author had in his mind. It was a case of rigidity rather than strength, and would not apply to flanges jointed with a more or less yielding material.

If ordinary flat flanges were referred to, he was in full agreement with the author's statement that the mere strength of a given flange was much greater if the packing extended over the whole surface. A specially designed flange adapted for a narrow joint could, however, be made with a smaller weight of metal than a flat one would have to be, when very high pressures had to be resisted without leakage. Fig. 1 (page 85) was one instance of this, and he knew of steam-pipe joints which had to stand a pressure of $250 \mathrm{lb}$. per square inch, to which the same remark applied.

Mr. James Nonman sent a drawing of a proposed joint for a 6-inch high-pressure water main. This scheme was intended to do away with flanges and bolts by using a right and left thread twin breech-block joint. The drawing showed that the threaded ends of the pipes were drawn together by turning the enclosing breechblock-coupling through one-sixth of a revolution.

* For instance, if the flange on the discharge branch of a circulating pump were bolted directly to a flange on a condenser, their relative angular position could not be adjusted as in that of a length of piping. 